\title{
ENTRE LAS POLÍticas de LO VIVIENTE Y LAS POLÍTICAS DE LA VIDA. \\ Hacia una antropología de la salud
}

\author{
DIDIER FASSIN \\ Escuela de Altos Estudios en Ciencias Sociales, \\ UnIVERSIDAD DE PARÍS 13, BobIGNY \\ dfassin@ehess.fr
}

\begin{abstract}
Resumen

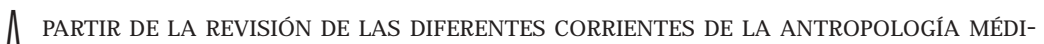
A ca, el artículo define los desafíos teóricos y metodológicos que enfrenta la antropología en el campo de estudios de la sal ud. Por ello, la antropología política de la salud propone una distinción fundamental entre lo viviente y lo vivo, en tanto la salud no constituye un problema ideológico, sino que integra una lógica social más amplia. Por un lado, el desarrollo de nuevas tecnologías médicas y, por otro, la puesta en práctica de políticas estatales sobre seguridad social, condicionan el acceso a los servicios de salud, reflejando las relaciones de poder que pesan en el gobierno de la vida y de la enfermedad.
\end{abstract}

Palabras Clave: salud, viviente, vivo, políticas de salud, inmigrantes.

\begin{abstract}
ThROUGH A REVIEW OF RECENT TRENDS IN MEDICAL ANTHROPOLOGY, THIS ARTICLE defines the theoretical and methodological challenges faced by anthropology in the field of health studies. As such, the political anthropology of health posits a fundamental distinction between what lives and what is alive, given that health itself is not an ideological problem. Rather, it integrates broader social logics. On one hand, the development of new medical technologies, and on the other, the implementation of state policies regarding social security, condition access to health services, reflecting the existing power relations that weigh in on the government of life and disease.

KEY wORDS: Health, alive, live, health policies, immigrants.
\end{abstract}

Revista Colombiana de Antropología

Volumen 40 , enero-diciembre 2004, pp. 283318 
ESE a que SUS LEgATARIOS INTELECTUALES haN CONSIDERADO ESTE concepto como uno de los más fecundos de su filosofía, Michel Foucault desarrolló poco su teoría del biopoder. En unas pocas páginas, al final de La voluntad de saber (1976: 177-191), enunció su famosa proposición: “Lo que podríamos Ilamar el 'umbral de modernidad biológi ca' de una sociedad ocurre cuando la especie se vuelve un desafío de sus propias estrategias políticas. El hombre ha sido durante milenios lo que era según Aristóteles: un animal vivo y además capaz de una existencia política; pero el hombre moderno es un animal en la política y para él su vida como ser vivo está en duda". Es así como se constituye el poder sobre la vida, que sabemos se ejerce según dos modalidades: por un lado, una "anatómico-política del cuerpo humano", mediante la cual las "disciplinas" someten al individuo a procedimientos que lo vuel ven apto para el buen funcionamiento de la sociedad y, especialmente, de la economía; por otro, según una “biopolítica de la población" en tanto las "regulaciones", Ias medidas e intervenciones controlan la especie y en particular los fenómenos relacionados con el nacimiento, la enfermedad y la muerte. Las dos modalidades están ligadas estrechamente: “El establecimiento durantela edad clási ca de esta tecnología de doble faz -anatómica y biológica, individualizante y especificante, di rigida hacia las puestas en escena del cuerpo y observadora de los procesos de la vida- caracteriza un poder cuya función más alta no puede seguir si endo matar si no conceder la vida en una y otra parte". Esta teoría, que había comenzado a elaborar durante su curso en el Colegio de Francia y sobre la que vol vería margi nal mente en artícul os ulteriores, quedó re lati vamente inacabada, puesto que ocho años más tarde, en Ios otros dos volúmenes de la Historia de la sexualidad, tomó otra alternativa, rica también: Ia exploración de los procesos de subjetivación por medio de los "empleos del placer" (1984) y el "cuidado de sí" (1984). Por más fugitivo que sea en la obra del filósofo -aunque algunos de los últimos textos publicados lo retoman de manera lateral mediante "la tecnología política de los individuos" (1994: 813828)-, este instante, en el que se esboza una teoría del gobierno de la vida, es con seguridad una etapa esencial.

En el ensayo titulado "Artificiality and enlightment: From sociobiology to biosociality" (1996: 91-111), Paul Rabinow no se equivoca. Retomando la dicotomía del biopoder, propone ver en la revolución de la biología y de las biotecnologías que representa 


\section{Revista Colombiana \\ de Antropología

la iniciativa para el genoma humano un sobrepaso y una reformulación de la anatómico-política y de la biopolítica: "Yo creo, escribe, que los dos polos del cuerpo y de la población se encuentran rearticulados en lo que podríamos Ilamar una racionalidad posdisci plinaria". Las perspectivas delas pruebas genéticas que permiten la racionalización dela responsabilidad individual y poblacional de las enfermedades parecen anunciar para él la constitución de grupos organizados con base en "nuevas identidades y prácticas", realizando lo que denomina la "biosocialidad". Por ejemplo, escribe, "no es difícil imaginar grupos formados en torno al cromosoma 17, locus 16256, sitio 654 376al el o variante con sustitución de una guanina: grupos así tendrán médicos especial istas, laboratorios, textos, tradiciones y una pesada panoplia de guardias pastorales ayudándoles a vivir, compartir, transformar y comprender su suerte". Así comenzará una era de "Ia artificial idad" que marcará la tercera gran crisis de la historia de la humanidad, según François Dagognet (1988): después de la revolución gali ileica que transformó nuestra relación con el universo, y de la revolución francesa que instituyó la idea de la producción de la sociedad por el hombre, esta última ruptura de la historia de nuestra mirada giraría en torno a la vida misma.

Tal lectura posdisciplinaria del biopoder, por más seductora que sea, enfrentaría el riesgo de ceder ella misma ante las seducciones de las sirenas científicas que anuncian, con los descubrimientos y las potencialidades de la genética molecular, el adveni miento de una nueva humanidad, si no fuera completada por otra lectura, atenta a los fenómenos más difusos pero no menos significativos de las formas actuales del gobierno de la vida y de las realidades menos espectaculares pero igual mente fecundas sobre el cuerpo. Al lado de las transformaciones por la ciencia de las representaciones y de las prácticas de sí, es importante tener en cuenta las múltiples manifestaciones de las relaciones de poder en lo más profundo del ser humano, en las diferencias de la esperanza de vida entre categorías sociales o entre países, e igual mente en los múltiples dispositivos de protección y de asistencia social desplegados nacional e internacionalmente. Cuando obra en el cuerpo la gobierno-mentalidad (gouvernementalité), definida por Michel Foucault (1994) como "el encuentro entre las técnicas de dominación ejercidas sobre los otros y las técnicas de cada uno", ésta se expresa tanto en las tecnologías médicas como en las políticas. De tanto enfocarse en 
los progresos de la biol ogía, sea para regocijarse de las perspectivas que ofrece $o$, inversamente, para denunciar sus peligros, uno podría olvidar las realidades triviales" del biopoder que revelan las políticas sanitarias y sociales así como la incorporación del orden político. Veríamos entonces reproducirse en el trabajo de anál isis realizado por las ciencias social es lo queen la producción de las reglas deacción de las sociedades ya condujo a reducir los

* Se han conservado las palabras señaladas en itálicas en el texto original ( $\mathrm{N}$. del t.). retos morales de la intervención sobre el cuerpo a las únicas cuestiones, perfectamente fundamen-

tadas después de todo, de la bioética, mientras que los innumerables y delicados problemas planteados por la salud pública quedarían esencial mente en la sombra.

Propongo agrupar esas real idades triviales dentro del vocablo salud. Así puede definirse la salud como la relación del ser físico y psíquico, por un lado, y del mundo social y político, por otro. Esto significa que es a la vez otra cosa y mucho más que el anverso de la enfermedad al que se la aproxima a menudo, o que la idea de bienestar gl obal que las instituciones sanitarias se aseguran de promocionar. Esta relación no es una particularidad de lo viviente, preexistente en la normalidad de un orden fisiológico, biol ógico o sensible y conducente a hablar de buena o mala salud. Al contrario, históricamente construida, es objeto de competencias y luchas entre agentes que se esfuerzan por imponer visiones diferentes sobre lo que concierne a la salud, es decir, lo que hace fal ta social y políticamente tratar como un problema de salud. A su vez, esta relación determina también las prácticas ordinarias y especializadas, las formas institucional es eideológicas del tratamiento de los desórdenes del cuerpo y de la mente. Lo que se denomi na comportami entos en materia de prevención y de enfermedad, políticas de salud y sistemas de cuidados, realidades que varían en el tiempo y según los contextos nacionales o locales, representa la traducción de esta relación. Es entonces esto lo que requiere ser aprehendido, no de manera abstracta, sino mediante los objetos concretos en los cuales se realiza: un programa de reducción de riesgos para usuarios de drogas por vía intravenosa en los suburbios franceses o de disminución de la mortalidad materna en las montañas andinas, un dispositivo de protección social o una consulta gratuita para los pobres, una modalidad de subsidio para los recursos sanitarios o una intervención humanitaria en los campos de refugiados. Lógicamente, 
estas real idades no son exclusivas a la exploración del genoma, de las pruebas y los consejos genéticos, de los saberes y las técnicas que se aplican en los cuerpos y transforman tanto a los individuos como a los grupos. Para decirlo de otra forma, desde el punto de vista del biopoder, es necesario rendir cuentas al mismo tiempo sobre lo que sucede en un centro de investigación del National Cancer Institute o del Instituto Pasteur, y sobre lo que ocurreen un servicio hospital ario de urgencias en la ciudad de Nueva York o en la asistencia pública de París, sin ceder antela magia de los primeros ni ignorar la banal idad de los segundos. Por lo demás, esteproyecto no es ajeno a la empresa de Paul Rabinow, quien se pasea desde los laboratorios sociales de los "French modern" (1989) hasta Ios espacios sabios del "French DNA" (1999). Entonces, en lugar de oponer las biotecnologías, que actúan sobre lo viviente, y las biopolíticas, que gobiernan la vida, la idea es ampliar el campo de lo que podríamos denominar las bío-lógicas, las lógicas sociales que ponen lo viviente y la vida a examen de la política.

En este texto** quisiera mostrar inicial mente cómo la antropología de la salud se diferencia de los enfoques tradicionales de la antropología médica y cómo, además, no puede ser aprehendida sin una doble lectura, histórica y política. En segundo lugar, meesforzaré en trazar la relación entre las dimensiones de objetivación y subjetivación presentes en la salud, es decir, des-

** Una versión abreviada de este artículo apareció en 2000 en la revista canadiense Anthropologie et Sociétés. Traducción del francés de $\mathrm{G}$ uillermo Vargas Q uisoboni. velar la tensión que existe entre la realidad objetivada por los epidemiól ogos o los economistas y su traducción subjetiva en las representaciones y las acciones. Tercero, intentaré dar ciertas bases para el anál isis de la rel ación entre los escenarios locales y mundial de la salud, lo que en otras palabras equivale a captar lo que está en juego en los fenómenos que podríamos Ilamar de globalización sanitaria. El carácter programático de esta reflexión -no se trata de realizar un estado de los lugares de la antropología de la salud sino de abrir perspectivas de investigación- responde por supuesto a la lógica de conjunto presente en la edición especial de esta revista. Por tanto, no se está partiendo de la nada. Sea que se consideren o no parte de la antropología de la salud, varios trabajos recientes, de los cuales al gunos serán evocados pero no todos podrán citarse, seinscriben en el proyecto definido aquí y muestran que la posición defendida, en el plano científico y desde el 
punto de vista político, es compartida cada vez más por los antropólogos. Intentaré de todos modos dirigir la reflexión hacia al gunas vías más nuevas delas cual es haré una síntesis, ligando al final políticas de lo vivo y políticas de la vida.

\section{DE LA ENFERMEDAD A LA SALUD}

A ANTROPOLOGÍA MÉdICA, SURGIDA EN LOS AÑOS 1960 EN EL SENO DE la antropol ogía estadounidense (Scotch, 1963), no forma un cor- pus homogéneo. Como lo han señalado sus analistas, especialmenteen Francia (Mitrani, 1982; Sindzingrey Zempléni, 1982; Walter, 1983), se organiza en torno a teorías heterogéneas y pol os múltiples que sólo razones prácticas, en particular la demanda social dirigi da a los antropólogos sobre el tema, a saber la construcción de un territorio científico propio, las Ilevarán a agruparse o a ser reuni das. Entre la antropol ogía bi ológica que busca los fundamentos genéticos del mestizaje (Benoist, 1966) y la antropología cultural orientada hacia las interpretaciones autóctonas de la enfermedad (Foster, 1976), entre la etnopsiquiatría que busca los lazos entre cultura y psiquismo (Devereux, 1970) y la etnomedicina que recoge el saber y las prácticas cultural es (Genest, 1978), entre el análisis de rituales terapéuticos (Corin, 1978) y el estudio de los itinerarios de las curas (Janzen, 1978), resulta muy difícil presentar una visión unificada de este campo reivindicado de nuevo (Fabrega, 1971). No obstante, hay dos el ementos comunes a la mayor parte de estos trabajos. Por un lado, su focal ización sobre la enfermedad: el enfermo y sus dolencias, el terapeuta y sus medicinas, o, dicho de otro modo, el individuo en las interacciones entre lo biológico y lo social, entre el poder y el saber. "Forma el emental del acontecimiento" (Augé, 1984), la enfermedad aparece como lugar de encuentro de la experiencia singular del enfermo o del terapeuta y de su socialización en el grupo. Por otro, su enfoque en términos de cultura: Ias representaciones y las prácticas de puebl os lejanos o en ocasi ones próximos, pero diferentes, o dicho de otro modo, el hablar siempre del otro y aprehenderlo bajo el ángulo de sus diferencias. "La medicina como sistema cultural" (Kleinman, 1980) apela a la búsqueda de los modelos de interpretación y tratamiento de la enfermedad singularizando cada una de las 


\section{Revista Colombiana \\ de Antropología

culturas. A la concepción individual izante dela enfermedad responde la construcción substancializante de la cultura. Mas al lá de las diferencias que pueden ser detectadas, Ia antropología médica "en la edad clási ca" estál ligada fundamental mente a este doble presupuesto.

Sin que las transformaciones producidas en el campo hayan sido coordinadas, diversos movimientos emprendieron desde hace poco más de una década su reconfiguración. Puede proponerse una lectura, sin pretender dar una visión exhaustiva, para señalar algunos de sus ejes de fuerza. Para comenzar, la antropología de la enfermedad, en terrenos alejados (A ugé, 1986) o próximos (Fainzang, 1989), confronta la legitimidad de la autonomía disciplinaria de la antropología médica: Ias ciencias social es no pueden reducir la enfermedad a simple objeto, aunque ello resulte particularmente iluminador frente a la unión del cuerpo físico y el mundo social, pero no se justifica en ningún caso fundar un campo aparte tal como intentaron sus promotores. Tras esta discusión epistemológica el objetivo es rechazar las mi radas demasiado cultural es que han prevalecido durante Iargo tiempo: el estudio de la ideología de las sociedades, cuya relación con la enfermedad y el infortunio ofrece una rejilla de lectura privilegiada, permite la articulación fuerte entre lo simbólico y lo político. Enseguida, la antropología de la experiencia, sea que sei interese por los rel atos de los enfermos (Klei nman, 1988) o por las representaciones de los médicos (Good, 1994), pretende sobrepasar los límites de la enfermedad, que en la antropol ogía médica siguen estando con demasiada frecuencia prisioneros de la construcción biomédica: al interesarse en el sufrimiento de los pacientes y en la racionalidad de los profesionales se ponen en movimiento categorías de análisis y formas de comprensión que desbordan el registro clínico. Sin abandonar del todo el enfoque cultural de la enfermedad, que conduce, por ejemplo, a buscar formas particulares de sufrimiento o de racionalidad en función de contextos particulares, estos trabajos suponen una puesta en duda parcial a partir de la búsqueda de rasgos más universales contenidos en la noción misma de experiencia, concebida como expresión dela subjetividad. Para terminar, la antropología médica crítica abre un tercer frente, sea que se inscriba en la perspectiva histórica (Taussig, 1987) o que proponga un enfoque contemporáneo (Scheper-Hughes, 1992): contra el funcionalismo implícito en numerosos estudios 
de antropología médica, este frente propone la lectura radical de Ia medicina, colonial o poscolonial, como práctica de dominación y de la enfermedad, o de su interpretación, como manifestación del orden social. Ahí en los escenarios donde el etnólogo centraba su mirada y con los anteojos de la cultura hay que concebir una economía política de la enfermedad dentro de la cual las relaciones de fuerzas internacionales encuentren su lugar, el papel de las instituciones médicas se analice y la posición del investigador mismo sea el objeto de mayor vigilancia. Estas tres direcciones no resumen probablemente la totalidad de las evoluciones dadas en el campo de la antropología en torno a la enfermedad. De hecho, las relaciones entre ellas fueron tan conflictivas que cuesta trabajo consi derar que participan de un mismo proceder (Morgan, 1990). Sin embargo, nos muestran ejes fuertes de replanteamiento de las primeras evidencias de la antropología médica. Sobre todo nos demuestran desde vías muy distintas el mismo interés en combatir la especialización y el aislamiento de la antropología médica, colocando los interrogantes quela enfermedad plantea a las sociedades en el centro de las preocupaciones de la antropología (Gaines, 1998). En el fondo se trata de la inversión completa de la tendencia anterior en la que se creía poder constituir un campo, no en ruptura, pero sí al menos al margen delas grandes corrientes del pensamiento y de la investigación de la antropología social. Desde entonces, la antropología médi ca se consi dera parte importante deuna reflexión antropológi ca más general.

No obstante, estos trabajos tratan esencial mente sobre la enfermedad entendida como evento integrante de una categoría más amplia del infortunio, como una experiencia descriptible en términos de sufrimiento o como una prueba reveladora de relaciones de poder. Pese a los diferentes enfoques, la dimensión individual de esta realidad social y de cómo la abordan los terapeutas se encuentra en el corazón de los tres proyectos intel ectual es. Sin embargo, en ellos pocas veces se presta interés a los sistemas de protección social y de higiene pública, a los programas de prevención de las epidemias y de lucha contra las grandes endemias, a las políticas internacionales de cuidados básicos y local es de la salud en la medicina comunitaria, a los proyectos de desarrollo sanitario en los países pobres y de desarrollo social en los barrios pobres de los países ricos, a los dispositivos de información epidemiológica y de regulación 


\section{Revista Colombiana \\ de Antropología

económica, todo lo cual constituye, en el fondo, la cotidianidad del campo dela salud. Habría que hacer aquí una salvedad con la antropología médica crítica (Singer, 1989) y con la economía política de la salud (Morsey, 1990). Por lo demás, la idea no es criticar la pertinencia de las orientaciones de estas "antropologías", sino revelar, más bien, una carencia, doblemente problemática. Se debe, por un lado, a la importancia que han adquirido estos interrogantes en las sociedades contemporáneas. En Francia, por ejemplo, con los procesos de sangre contaminada que implicaron a ministros y la definición del principio de precaución, la controversia sobre los efectos patógenos de lo nuclear y el cuestionamiento de la acción pública en materia de medio ambiente, el informe oficial sobre al coholismo como fármaco-dependencia y el debate sobre la despenalización de la marihuana, la reforma a la seguridad social y los debates en torno a la solidaridad nacional, al lugar de la medicina humanitaria asociativa en la gestión dela miseria y a las prácticas de apoyo humanitario de los hospitales públicos. Por otro lado se debe al significado que tiene esta ausencia para la antropología: lejos de ser accidental , esto remite hacia la preferencia habitual de la disciplina por objetos más nobles y menos ordinarios y, al mismo tiempo, implica una distancia que se manifiesta con frecuencia con respecto a los interrogantes de sociedad, sobre todo los más urgentes o los más actuales. Como reconoce, a propósito de sus propios trabajos, Arthur Kleinman (1995) en la introducción de una obra, "escribir en 1994 sobre la medicina y no situarse en el debatenacional americano sobrela seguri dad social es afirmar otra forma de marginalidad" de la antropología médica. Merril Singer (1995) estigmatiza el desinterés por los desafíos políticos de la salud en un texto en el que solicita el compromi so de los antropólogos médicos con la "praxis crítica". Pero la falta de interés por esos objetos desencantados no es al go excl usivo del campo de la sal ud: "Ia antropología política de la modernidad" (Abélès, 1992) pretende, precisamente, al imentarse de estos hechos y estas escenas quese nos volvieron incontrolables por tanta familiaridad con ellas o, simplemente, por lo poco exóticas que son.

La idea defendida aquí es que en estos caminos aún poco visitados por la antropología, donde lo social es y existe sin encantamientos, donde lo banal se enfrenta con lo técnico, donde los aspectos administrativos disfrazan las dimensiones morales, donde las fronteras entre aplicación eimplicación parecen ser las 
más indecisas, es justamente donde los retos se tornan más cruciales para el mundo contemporáneo y, desde luego, para las ciencias social es. No se trata de meter la antropol ogía en el diapasón de los problemas de sociedad, de someterla a una supuesta demanda social o de hacer de ella una ciencia especializada queformula recomendaciones, sino consi derar que esas reali dades aparentemente trivial es de la sal ud son al menos tanto como la enfermedad y la medicina portadoras de senti do y requieren en consecuencia un trabajo de interpretación. A este respecto, son paradójicamente los historiadores antes que los antropólogos quienes han abierto el camino. Los trabajos pioneros deEdwin Ackerknecht (1948) sobre la higiene y el anti-contagionismo, de Henry Hatzfel d (1971) sobre el desarrollo de la protección social francesa y de Carlo Cipolla (1976) sobre los comités sanitarios ital ianos de finales de la edad media, mostraron hasta qué punto las investigaciones en sal ud pública podían aclarar las grandes evoluciones de las ideas y de las instituciones, exploración que se prol onga en obras recientes sobre las ciencias y las técnicas (La Berge, 1992), sobre las representaciones y las sensi bilidades (Vigarello, 1993) o sobre las poblaciones y sus dinámicas (Bourdelais, 1994). La historiografía colonial abordó también los problemas de poder y de saber, las relaciones de dominación y de violencia, los desafíos social es y políticos que ponían en evidencia el estudio de las endemias (Lyons, 1988), las epidemias (Ranger, 1992), las hambrunas (Vaughan, 1992) o la psiquiatría (McCulloch, 1994), que tenían lugar en el continente africano. Desde este punto de vista, la selección de textos recogida por Steven Feierman y John Janzen (1992) constituye un verdadero manifiesto para una antropología histórica de la salud: más aún que las declaraciones teóricas liminares, es el val or de los estudios de caso que, a partir del análisis de las condiciones socioeconómicas de producción de la tuberculosis en Sudáfrica (Packard, 1992) o de los modos de legitimación sanitaria de las políticas de urbanismo en África central (Curtin, 1992), revelan las lógicas de poder y sus efectos sobre el cuerpo en el orden colonial. Lo que pone de manifiesto la historia, bien sea en manos de los historiadores o de los antropólogos (Dozon, 1985), es que el estudio de la salud comienza ahí donde la enfermedad, saliendo de la relación supuestamente confidencial entre el paciente y el terapeuta, incluye al cuerpo social : Ia investigación sobre la endemia de tifo en Sudáfrica en la primera mitad del 


\section{Revista Colombiana \\ de Antropología

sigl o vei nte nos habla de la sal ud como forma de control social, especial mente en la escogencia de medidas tendientes menos a la eficacia sanitaria que a la intervención y la represión de las protestas, y como revel adora de las rel aci ones social es, la infección que afecta exclusi vamente a las poblaciones negras pauperizadas, pero interpretada por los poderes públicos como la consecuencia de su desi dia y suciedad (Marks y Anderson, 1988). Así, mejor que como pudo hacerlo la antropología, la historia del mundo moderno, ya sea occidental o colonial, adquirió la medida del interés que podía haber en estudiar la salud al mismo tiempo como significado y significante del cambio social, esto es, por los sentidos que porta y por los signos que representa. Este doble registro de interpretación es el que hace falta poner en práctica en la antropología de la salud.

¿Pero de qué sal ud estamos hablando? Para responder a esta pregunta podemos intentar trazar su etimología. Sabemos que la antropología médica se alimentó de una reflexión basada en las tres pal abras ingl esas para designar la enfermedad: disease, la patol ogía identificada por la medicina; illness, Ia experiencia subjetiva del paciente; sickness, el fenómeno social que produce el libreto del enfermo y las expectativas de la sociedad. Incluso si estas distinciones fuerzan un poco las regl as lingüísticas y si las categorías así constitui das pueden parecer simplificadoras frente a la complejidad antropológica, tienen la utilidad de deconstruir una noción con sentido propio. Un ejercicio similar puedeproponersea partir del latín para la palabra salud. En efecto, existen tres términos diferentes para designarla. El primero es salus, que expresa el buen estado físico y moral, pero también la salvaguarda de los bienes y los derechos propios. El segundo, sanitas, indica también el buen estado del cuerpo y del espíritu, pero puede significar, así mismo, la razón, el buen sentido, el buen gusto. El tercero, salubritas, añade a la noción de buen estado de sal ud la i dea de los medi os que permi ten conservarlo. Sin poner mucho énfasis en esta etimología, de la cual ciertos trazos subsisten en el francés contemporáneo, pero más aún en español, podemos recoger dos enseñanzas. Por un lado, la nebuIosa original de la salud no se reduce a las dimensiones de lo corporal y lo médico, toca también aspectos jurídicos, morales, intelectuales y tecnológicos que el reduccionismo sanitarista tiende a escamotear. Por otro, cada uno de los términos latinos se presenta unido a tensiones que son, precisamente, las que 
atraviesan hoy en día el dominio dela salud: para salus, entre lo físico y lo cívico, entre el bien y el derecho; para sanitas, entre lo patológico y la norma, entre la racionalidad y el valor; por último, para salubritas, entre lo individual y lo colectivo, entre lo técnico y lo político. Si la idea aquí no es dedicarse a un verdadero trabajo lexicológico, al menos podemos ver que el empleo habitual de la palabra salud, en francés particularmente, opera una restricción semántica consi derable con respecto a su riqueza etimológica. Es entonces en esta riqueza etimológica que es necesario anclar, como propone Raymond Massé (1995), la comprensión renovada de una noción potencial mente heurística, puesto que hace entrar en juego significados ol vidados en la lengua, pero todavía presentes en el mundo social .

Para poner orden a esta profusión puede partirse de la tipología sugerida por Margaret Lock y Nancy Scheper-Hughes (1990: 47-72). A fin de renovar las visiones tradicionales de la enfermedad y basándose especial mente en los trabajos de Mary Douglas, ellas proponían una triple lectura del cuerpo: el "cuerpo individual, entendido en el sentido fenomenológico de la experiencia vivida del cuerpo propio", sin distinción de sus dimensiones material y espiritual; el "cuerpo social, refiriéndosea las representaciones del cuerpo como símbolo natural a partir del cual pensar I a natural eza, la sociedad y la cul tura", donde la enfermedad viene a ser el emento a la vez perturbador y revel ador; y el "cuerpo político, implicando la regulación, Ia vigilancia y el control delos cuerpos individual es y colectivo en la reproducción y la sexualidad, el trabajo, el tiempo librey la enfermedad", por medio delos cual es la normalización puederevestir formas múltiples, desdeel compromiso violento hasta el autocontrol. Sin embargo, esta interesante clasificación se arriesga a dejar de lado el hecho que el cuerpo individual es en sí mismo siempre también un cuerpo social y político (Turner, 1992), y es justamente lo que la definición precedente de la salud intenta enunciar. Esto explica por qué en una investigación precedente (1996) había propuesto definir un espacio político de la salud y describirlo estructurado en torno a tres ejes que podían ser tantos como las dimensiones a caracterizar por medio del trabajo empírico: la incorporación de la desigualdad, realizando la inscripción del orden social en los cuerpos, sea por ejemplo en el caso de la marcación ritual en las sociedades tradicionales o en el de las disparidades frente a la muerte en las contemporáneas; el poder de curar, derivado de la 
legitimación de grupos reconocidos competentes para intervenir sobre la enfermedad, como los chamanes, los morabitos o Ios médicos; finalmente, el control sobre la vida, poniendo en acción la gestión col ectiva de la salud como bien público, desde las antiguas prácticas propiciadoras hasta los programas de prevención modernos. En el fondo, se trata deconstituir una antropología política de la salud con sus respectivas decl inaciones en antropología política del cuerpo, de la medicina y de la salud pública. Para ello, ahora es necesario comprender mejor cómo el doble trabajo de objetivación y de subjetivación de la salud organiza esta antropología.

\section{OBjetivación y SUBjetivación}

\section{L inicio de su Filosofía de la salud, Hans-George Gadamer (1998: 7) se cuestiona sobre la especifici dad dela medición en este campo:}

la física de nuestro siglo nos enseñó que hay un límite en la posibilidad de medir. Esta observación me sugiere un problema hermenéutico fundamental que se plantea con más agudeza en el caso del hombreviviente que en el de la simple naturaleza medible. Porque entonces el problema de los límites de la posibilidad de cual quier medida y más generalmente de cual quier acción se sitúa en el corazón mismo de la ciencia y de la práctica médica.

Y concluye diciendo: "la salud no es una cosa que se fabrica". Tres presupuestos sostienen esta reflexión: primero, lo viviente humano es una forma particular denatural eza; segundo, la sal ud es un atributo delo viviente; y tercero, la medición dela salud es una objetivación de este atributo. En contra de esta triple aserción propongo construir una antropología de la sal ud. Ya sea, pal abra contra palabra, primero, lo vivientehumano tal como lo aprehendemos resulta de un juego entrenatural eza y cultura; segundo, la sal ud es una producción social, pues la sociedad define lo que posee salud o, más bien, da una expresión sanitaria a ciertas realidades en lugar de otras; tercero, el trabajo de objetivación contribuye a esta producción y entonces sevuel veinseparable deuna operación desubjetivación. Detengámonos un instantesobreestas tres proposiciones para explicitarlas eilustrarlas. 
Dado que la enfermedad afecta al cuerpo y quela medicina ha mostrado sus resortes más escondidos, desde la fisiología y la anatomopatología que exploraban lo macroscópico de la enfermedad hasta la inmunología y la genética molecular que trabajan con sus dimensiones más el ementales, lo viviente humano parece inscrito en la naturaleza. Quizá nadie sueña en negar que el cáncer es una realidad histológi camente verificable o que el genoma codifica las proteínas que conforman la materia corporal . Pero, ¿acaso lo viviente no es algo más que una naturaleza? O mejor, ¿existe hoy una natural eza que esté virgen de toda "contaminación" cultural? En el caso del cáncer, hay queconsi derar evidentemente pensar el mesotelioma como una simple realidad biológica quemanifiesta la proliferación de células malignas en la piel, o una enfermedad rel aci onada con la intervención humana, provocada por una exposición ante el asbesto y en particular durante el trabajo. Su reconocimiento como "enfermedad profesional" es el fruto deluchas social es que muestran hasta qué punto la producción y la cualificación de los hechos de la sal ud son un desafío político (Thébaud-M ony, 1991). En el caso del genoma, no hay que conformarse con los implícitos, en ocasiones ya explicitados, de los genetistas que tanto de forma poética como profética hacen del encadenamiento del as bases en una estructura de ADN Ia clave de la herencia no solamente de las enfermedades sino también de los comportamientos. Si uno puede convenir tranquilamente que los genes tienen existencia material y son el soporte dela transmisión de caracteres, no hay que pasar por al to que son, al mismo tiempo, "íconos cultural es" mediante los cuales se expresan representaci ones más o menos fantasmal es de la sociedad sobre ella misma, como lo demuestra la fascinación ejercida por el descubrimiento de los genes de la homosexual idad o dela violencia (Nelkin y Lindee, 1998). La mi sma construcción de lo viviente y de la vida, por sus consecuencias morales, sobre las cuales habrá que regresar después, es productora de objetos de cultura tanto como de natural eza. Esta doble relación de culturalización de la naturaleza y de naturalización de la cultura es lo que debe enfrentar el análisis antropológico de la salud, partiendo de que esta rel ación no puede ser aprehendida más que como históricamente constituida y políticamente significante. Inspirándose en la antropología de la ciencia que estudió esta relación en el marco reducido del laboratorio (Latour y Woolgar, 1993), se trata de portar el análisis sobre un mundo social más amplio en 


\section{Revista Colombiana \\ de Antropología

el que la noción de riesgo se ha convertido en una mediación insuficientemente problematizada entre natural eza y cultura (Douglas, 1992). La salud pública en tanto que escena cotidiana de puesta en práctica de esta mediación ofrece un objeto de estudio particularmente heurístico, aunque poco estudiado desde este ángulo.

En efecto, las pruebas de que la sal ud no está dada si no que se produce social mente abundan en la historia. Basta con evocar lo que se denomina "maltrato infantil" (Pfohl, 1977). La violencia hacia los niños, un problema esencial mente privado vinculado a la autoridad paterna, ingresó a la esfera pública a finales del siglo diecinueve, convirtiéndose en objeto de una legislación represiva cuya aplicación efectiva fue, por lo demás, progresiva y tardía. Paralelamente, el mal trato a niños se volvía poco a poco preocupación mayor de los trabajadores sociales. No fue sin embargo hasta la segunda mitad del sigl o veinte que se convirtió en una realidad de salud, real izando una doble operación de identificación y cualificación, como se demostró en otro texto (1998a). La primera operación se trata de una medicalización: surgeen los años 1960 con la descripción de los radiólogos de un síndromedel niño maltratado relacionado con la existencia de múl ti ples fracturas de los miembros y el cráneo. La segunda realiza una politización: en el transcurso de la década de 1980 convierteesta entidad médica en problema de salud pública asociado principalmente con los suburbi os considerados más difíciles y supone la aplicación de programas preventivos. Esta traducción de una realidad social puede asimilarse a una real idad sanitaria como un trabajo de producción de la salud, en el sentido en que MauriceGodelier y Michel Panoff (1998) hablan de "producción del cuerpo", en la que los agentes movilizan con o sin intención sus competencias y al ianzas para imponer su propio sentido del orden de las cosas en contraposición de otros sentidos. Esta nueva realidad no es inerte y sigue siendo el objeto de actividades de transformación: así pues, el contenido del mal trato, reportado inicialmente como violencia física, familiar con frecuencia, tiende a cristal izarse en torno a la violencia sexual, y particularmente al incesto (VigareIlo, 1998). Mediante esta breve evocación de la historia del maltrato infantil se busca poner en evidencia el proceso por el cual una realidad social es reconocida como parte de un registro de la salud, y en este caso de la salud corporal y la salud mental. Reconocimiento que no es una simple operación abstracta de 
clasificación si se consideran sus consecuencias concretas en la acción: el problema nuevamente identificado y cualificado se convierte en el objeto de una intervención sanitaria que convoca lógicamentea los profesi onales de la salud, pero también a los de lo social, de la pedagogía, de la animación y el tiempo libre, en el marco de unos programas de salud pública en los que todo sufrimiento físico o psíquico se desi gna como el objetivo de la acción común.

Ciertamente podría hacerseel razonamiento inverso, pues para que haya traducción al lenguaje de la sal ud hace falta, necesariamente, que haya un daño en el cuerpo o en la mente, o dicho de otro modo, un fundamento biológico o psicológico que justifique esta operación. En el fondo no habría que descubrir lo que ya existe. La prueba sería el hecho objetivable por la medición epidemiológica en particular, la realidad que la sociedad considera haber producido, pero que en la práctica no ha hecho más que nombrar. Pero este análisis pasa por alto dos cosas. Por un lado, el hecho dequeexisten siempre múltiples maneras de identificar y de cualificar un problema: su inscripción en el campo sanitario no es más que una de ellas, pero también en este contexto puede tomar expresiones muy diferentes. Por otro, el hecho que esta identificación y esta cualificación proceden de juegos de poder y de conflictos para imponer una visión contra otra: un análisis sociológico de las relaciones de fuerza y de dispositivos de controversia pone así en duda la inmanencia de la verdad de lo viviente. Ilustremos estas palabras con el caso de la toxicomanía. “¿Qué es el consumo de drogas?, se pregunta Albert Ogien (1994: 9). ¿Es un sufrimiento, un desorden neurofisiológico, una epidemia, una conducta marginadora, un delito o un capricho de adolescentes? Es quizá todo esto a la vez y cada una de estas cosas por separado". Ahora bien, entre estas diferentes significaciones la sociedad escoge, pero no realiza las mismas escogencias en todo lugar ni en todo momento. Para limitarse a su forma más claramente circunscrita, el uso de drogas por vía intravenosa aparece primero social mente como una desviación y, en no pocos países, jurídicamente como un delito. Esto significa que el toxicómano muestra antes que nada un registro represivo puesto en práctica por la policía y la justicia. Pero desde hace un buen tiempo la psiquiatría se interesó por los drogados y más particularmente por su situación de dependencia, poniéndose como objetivo primero de su intervención la eliminación 


\section{Revista Colombiana \\ de Antropología

dela dependencia. Dentro deesta perspectiva, la medical ización dela toxicomanía busca la cura física suponiéndola correlacionada al mejoramiento físico. Cuando sobrevino la epidemia del sida, a comi enzos de los años 1980, I os consumi dores de drogas por vía intravenosa fueron reconoci dos de inmediato como unos de los principal es "grupos de riesgo". Pese a ello, estos grupos se mantuvieron por fuera de los programas de prevención por mucho más tiempo que las otras categorías identificadas en función de los modos de transmisión. Para retomar la expresión de Ronald Bayer (1992), el los fueron las princi pales víctimas de la "política de negligencia de las autoridades sanitarias". La nueva realidad no cuadraba dentro de la al ternativa de represi ón-cura que primaba: la prevención, que consistía en reducir la transmisión infecciosa a la vez mediante la distribución masiva de productos de substitución y del acceso a jeringas estériles, termi nó aceptando por un Iado una práctica ilícita y por el otro renunciando a su lucha contra la dependencia. Por esto mismo existen diferencias significativas entre los países en la rapidez para superar tal es contradicciones y conflictos iniciales (Steffen, 1995). En Francia, la tardanza en la expedición de reglas nacionales y en su aplicación local se relaciona, ciertamente, con factores generales, en particular con la estigmatización de los toxicómanos, su frecuente pertenencia a entornos miserables y su baja capacidad de movilización colectiva, pero también con aspectos más específicos, como la fuerte resistencia profesional de la corporación psiquiátrica y la ausencia de legitimi dad dela sal ud pública en el espacio social (Lovell y Féroni, 1998). Sólo después de concl uida la lucha entre diferentes visiones de la toxicomanía como delito, sufrimiento y riesgo, la salud pública pudo, quizá no imponerse pero sí al menos ser admitida como uno de los principios de gestión. El desarrollo de programas de metadona y la instal ación de máquinas automáticas de venta de jeringas, aunque de manera tími da, son los signos de esta inscripción de la toxicomanía en el campo de la salud pública. Operación esta que no es simplemente de orden regla mentario, sino que encuentra su concreción, por ejemplo, en las formaciones de guardias residencial es en el curso de las cual es se intenta modificar la imagen del drogado, haciéndolo pasar del estatus dedel incuenteamenazanteal deenfermo expuesto al riesgo de contaminación. Estos desplazamientos de representación de hecho no son estables y constituyen permanentemente el objeto de renegociaciones. Tanto en los consejos comunal es de 
prevención de la delincuencia donde están instal ados los elegidos de la salud y de la seguridad como en los barrios donde se codean asociaciones y policías, los primeros se esfuerzan por imponer sus lógicas sanitarias en contraposición a las lógicas de seguridad de los segundos. Como este ejemplo pretendemostrarIo, el estudio de los fenómenos de salud debe entonces evitar tanto la traba del positivismo que supondría que la sal ud preexiste y que el trabajo de conocimiento, ya sea médico o biológico, no tiene otro objetivo que el reconocer lo que ya es, y el peligro del relativismo, que reduci ría la sal ud a un simple efecto de convención entre agentes que convienen decir lo que resulta deella, independientemente de toda real idad material (Woolgar y Pawluch, 1985. El constructivismo aquí empleado pretende ligar los hechos biológicos y los sociológicos, estableciendo en particular cómo el trabajo de objetivación es indisociable del trabajo simultáneo de subjetivación.

Delo que setrata más exactamentees deaprehender no la línea dedemarcación entrel o que dependedela salud y lo que no hace parte de ella, ni tampoco la actividad de los agentes que pretenden desplazar esa línea reformulando las cuestiones de sociedad mediante problemas sanitarios. Antes quela operación de definición y deconstrucción en sí misma, son los retos quela sostienen los que nos interesan, como intenté mostrarl o en otro texto (1999). ¿Qué es lo que ocurre en las discusiones y las controversias que buscan hacer del mesotel ioma un cáncer profesional, del genoma un soporte hereditario de los comportamientos, del maltrato infantil un problema de sal ud pública, delos consumi dores de drogas por vía intravenosa un grupo de riesgo? ¿Qué es lo que se busca en las relaciones de saber y de poder que movilizan estas definiciones y estas construcciones? Tales son las preguntas que plantea a la antropología la producción de la salud. Las respuestas iluminan los retos eminentemente políticos, en el sentido de que atraviesan los tres fundamentos de lo político: para comenzar, implican relaciones de poder y de legitimidad sobre los territorios, según pal abras de Max Weber (1978); I luego, conciernen las fronteras entre el espacio público y la esfera privada, lo que Julien Freund (1986) pone en exergo; finalmente, y en una acepción más amplia, tocan el problema de vivir juntos, es decir, el problema de la pluralidad humana y desus consecuencias en térmi nos de comuni dad y de solidaridad, para retomar la definición de Ana Arendt (1995). De hecho, la salud somete estas 


\section{Revista Colombiana \\ de Antropología

tres dimensiones de lo político a una prueba singular, que es la del cuerpo, es decir, al dilema de lo viviente y de la muerte, de la enfermedad y el sufrimiento. Como lo ha mostrado precisamente el proceso de la sangre contaminada en Francia que obligó a que se exami nara a mi nistros, estas necesi dades confieren al registro de la salud una tonalidad particular en la gestión de los asuntos públicos.

Lo que debe comprenderse es ese estatus singular que se le confiere a la salud. El caso del saturnismo que evoqué en una investigación precedente (1998b) lo ilustra perfectamente. Se trata de una intoxicación con plomo conocida hace bastante tiempo, representada desde comi enzos de siglo en las viejas pinturas y que sobreviene esencial mente en Francia en el hábitat vetusto y precario de los barrios y suburbios antiguos de las grandes aglomeraciones, en especial a las afueras de París. Teniendo en cuenta las real i dades soci oeconómicas locales, son esencialmentelos niños de origen extranjero provenientes en su gran mayoría del África subsahariana quienes resultan afectados: a los fenómenos clási cos de segregación urbana se suma en efecto la dificultad particular quetienen estas familias, víctimas dediscriminación, de acceder a la vivienda social, por lo que se confinan al parque privado degradado. Después de la muerte de un niño en París y la deotro en una ciudad obrera limítrofe, seinicia una movilización a finales de la década de 1980 entre las asociaciones de habitantes y también entre los servicios comunitarios de higiene. Los estudios epidemiológi cos muestran la extensión del problema, mucho más grande de lo que se esperaba. El problema emerge en el espacio público pero su inclusión dentro de la agenda política se tropieza con obstácul os importantes. Por un lado, las características de la población afectada por la enfermedad no le llaman la atención a los políticos el egi dos: en un contexto incesantemente reconocido por la ascensión electoral de la extrema derecha que hizo de los inmigrantes sus chivos expiatorios, no resulta conveniente parecer interesarse demasiado en grupos que por si fuera poco no votan. Por otro, las dificultades financieras y jurídicas hacen de la prevención al go particularmente poco eficaz: la reasignación de vivienda y la rehabilitación le salen caras a la colectividad y los medios para presionar a los propietarios inescrupulosos resultan insuficientes. En el curso de los años 1990, al gunas municipal idades comienzan, sin embargo, a tomar conciencia de la gravedad del problema y, por tanto, intervienen, primero 
modestamente, después con mayor generosidad. Paral elamente, las presiones locales al canzan a generar efectos nacional es y la ley consagrada según dicen "a la exclusión" votada en 1998incluye importantes avances regl amentarios y económicos para la prevención del saturnismo, la única enfermedad explícitamente mencionada en el texto legislativo. ¿Qué puede decirse de esta epidemia? En primer lugar, que muestra a la vez los estigmas físicos del orden social -las poblaciones víctimas de la segregación espacial y de la discriminación en el acceso a vivienda se ven marcadas en sus cuerpos- y las reticencias políticas para comprometerse en programas en beneficio de las categorías margi nadas -los inmigrantes son el arquetipo y no la excepción, como se anotó en relación con los toxi cómanos-. En segundo lugar, muestra que ahí donde las condiciones indignas de la vivienda no obtenían eco entre los poderes públicos, la evidencia de un sufrimiento corporal pudo generar una reacción social y política -que la intoxicación afectara esencialmente a niños aumentaba aún más el dramatismo dela situación-. Positivistas y relativistas terminan dándose la espalda. Ciertamente, no basta con que la patología exista para que constituya un problema de salud: primero falta que la movilización de agentes le otorgue existencia social. Pero sin la objetivación obtenida mediante las investigaciones toxicológicas, la subjetivación no toma cuerpo: al punto que el problema del umbral de gravedad se vuel ve un elemento de discusiones científicas y políticas, puesto que compromete al tiempo el futuro, en particular el intel ectual del niño y las disposiciones concretas en relación con la severidad del sufrimiento, lo que significa su reubicación o su rehabilitación. Fal ta, sin embargo, ir más lejos y preguntarse sobreel sentido de esta sanitarización de lo social, es decir, esta traducción sanitaria de un problema de sociedad, en estecaso de las condiciones de vida de losinmigrantes.

¿Por qué como en este caso el mundo social está más cercano de reconocer las desi gual dades y las injusticias de que son víctimas las poblaciones de origen extranjero cuando existe sufrimiento físico y no cuando las regl as el emental es de la dignidad humana son burladas? ¿O simplemente por qué los poderes públicos están más prontos a actuar ante un problema de salud y no ante uno de hábitat? La hipótesis que puede manejarse es que en la definición deestas prioridades hay un reconocimiento más grande sobre la integridad del cuerpo que sobre la de la persona, o 
para decirlo de otra forma, el reconocimiento de la persona pasa antes por el reconocimi ento del cuerpo al terado o sufriente. Sugiero denominar bío-legitimidad a esta prioridad dada a lo viviente en la administración de los asuntos humanos. Aquí no hay que confundirse. No se trata de hacer de este concepto una especie de principio superior universal, sino de caracterizarlo como uno de los fundamentos moral es del mundo contemporáneo. No hay entonces que pensar en proponer una visión teleológi ca del curso de las cosas haciendo de la sanitarización una nueva ley de la historia, pero sí ubicar un proceso recurrente y significante, no exclusivo evidentemente de otras lógicas. Se sabe que Giorgio Agamben (1997) propone rendir cuenta de la biopolítica a partir de la oposición de los dos términos griegos que significan la palabra vida: zoé, la vida biológica, que éste denomi na vida desnuda, y bíos, la vida en sociedad, a la que también Ilama vida política. Lo que expresa la idea de bío-legitimidad es la fusión de estos dos significados, o quizá más exactamente la refundación de la vida política en la vida biológica. Lejos de limitarse al campo tradicionalmente definido de la sal ud, este planteamiento es un gran avance. Se encuentra en el corazón de lo que podríamos llamar la lógica humanitaria, que va mucho más al lá de la medicina humanitaria que le concedió sus documentos de nobleza. En esta lógica, presente en los campos de refugiados de Ruanda o entre los desplazados de Kosovo, así como en las consultas para pobres de los dispensarios asociativos o de los hospital es públicos, la vida, o mejor la supervivencia, se convierten en la justificación última de la intervención, así sea de carácter militar. Los derechos del hombre, en cuyo nombre se proclama la urgencia de la acción, son derechos del humano viviente antes que del ciudadano del mundo. La ambición de universalidad que ellos anuncian se encuentra reducida a su más simple expresión: la desnudez de la vida.

\section{GlobalizaCión y SIGNificACIÓN}

OS DESLIZAMIENTOS DE ESCALA QUE ACABAN DE SER EVOCADOS -ENTRE lo local y lo gl obal, para retomar una oposición geertzianaL convocan a la reflexión sobre lo que está en juego para la antropología en general y para la antropología de la salud en 
particular en el trabajo social por el cual las realidades sanitarias se vuelven cada vez más interdependientes y los val ores morales se tornan cada vez más generalizadores. Si bien la antropología médica, singularmente por medi o desus corrientes críticas, se ha apoderado de la internacionalización de la sal ud (Nichter, 1994; Yoder, 1997), puede ser que aún no se haya al canzado la compl eta medida de la globalización de las bío-lógicas. Tal es el propósito de este apartado. A este respecto, la literatura consagrada a la "antropol ogía dela gl obalización", especial mente la sel ección ya clásica de Arjun A ppadurai (1996) portan más sobre la dimensión cultural, con una singular fascinación hacia los fenómenos de mestizaje o de hibridación por un lado, y hacia los encerramientos étnicos o fundamentalistas por el otro, sin enfatizar sobre la dimensión sociopolítica de las real i dades descritas y la distancia con respecto a su construcción. Probablemente, este defecto de análisis político es la causa de la desconfianza que le despierta a Pierre Bourdieu y Loïc Wacquant (1998) el uso, en el trabajo intelectual, de esa palabra mágica mediante la cual la ideología neoliberal sepresenta como un camino hacia el futuro sin al ternativas. Al sugerir aquí unir lo local y lo gl obal dentro del estudio de las biopolíticas y proponer hablar de globalización de la salud nos situamos dentro de la perspectiva de una antropol ogía crítica (Packard, 1989), no exclusiva en todo caso de la implicación del investigador en los programas sanitarios (Hahn, 1999). Pero esta termi nología no es enteramente clara. Para acudir a dos referencias contrastadas, vemos bien que cuando Clifford Geertz (1986) caracteriza sus trabajos con "un ritmo conceptual interno", efectuando un "ir y venir dial éctico continuo entrelo más local delos detalles local es y la más global de las estructuras globales, de suerte que se ll ega a verlos si multáneamente", en el fondo se sitúa en la línea del hecho social total de Marcel Mauss, procurando unir el todo y las partes, mientras que Michael Kearney (1995), en su revista de literatura sobre el asunto definió la globalización a partir de "Ios procesos sociales, económicos, culturales y demográficos producidos en las naciones pero superándolos, de tal manera que la atención focalizada únicamente sobre los procesos, identidades y unidades de análisis local conduciría a la comprensión incompleta de lo local", inscribiéndose así en la tradición braudeliana de análisis de los "sistemas-mundos". Antes quela oposición entre dos significaciones, la primera conducente a la totali dad de lo local, I a segunda a su resonancia mundial, Io 
que se produce es un deslizamiento de sentido: I o que eran en la década de 1980 lo local y lo gl obal para los antropól ogos no puede ser superpuesto a lo que se han convertido en los años 1990. EvoI ución semántica en suma banal , debe considerarse, sin embargo, como una sedimentación antes que una substitución. La lectura atenta del número de textos recientemente publicados sobre el asunto muestra de hecho frecuentes pasajes entre uno y otro sentido. Por tanto, al referirse a los "juegos de escala" de los que habla Jacques Revel (1996), no hay que considerar entonces queel movimiento entre lo local y lo global incluye indisociablemente una doble dimensión: metodológica, por un lado, articulando lo micro y lo macro; teórica, por el otro, uniendo las reali idades social es einternacionales.

Aprehendida en el campo dela salud, la gl obalización implica principal mente dos procesos. En primer lugar, se trata de la interdependencia mundial de los determinantes de la sal ud (Browner, 1989). Para decirlo simplemente, el estado sanitario de una población observada en un pueblo o un barrio, donde quiera que sea, está estrechamente relacionado con las rel aciones de fuerzas internacionales. No es posi ble anal izar las tasas de mortalidad, las inci dencias de enfermedad, las tendencias de desnutrición localmente constatadas sin inscribirlas en la historia social, demográfica, económica y política dela región, del país y del mundo. Sin duda el impacto de estos diferentes niveles es variable según las situaciones, pero la interpretación debe procurar mantener precisión sobreel lugar correspondientey sus lazos. Esta primera oposición resuena como un estribillo olvidado y coincide con una "economía política de la salud" (Doyal, 1979) col ocada muy rápidamente entre las herrami entas sobrepasadas por las nuevas realidades del mundo. A diferencia de tales trabajos pioneros, el trabajo que esta supone permite comprender, especial mente mediante las bi ografías y las monografías, cómo el orden internacional o nacional encuentra su traducción en las representaciones, las prácticas y las condiciones local es: es lo que hace Paul Farmer (1992) en su estudio sobre la epidemia de sida en Haití, en el que muestra cómo las relaciones políticas y si mbólicas en el seno de la sociedad haitiana, por un lado, entre la isla y Estados Unidos, por el otro, determinan un dispositivo complejo de sospecha y acusación que tiene consecuencias concretas sobre la condición misma de los enfermos. En segundo lugar, hay que ocuparse dela circulación mundial de los model os de salud (Zimmermann, 1995). 
No se trata sól o de constatar la difusión planetaria de los conocimientos, las tecnologías y los productos de la medicina. Es aún más extenso y, puede pensarse, de manera más decisiva todavía, el movimiento de las ideas, las imágenes, los procedimientos y los métodos. Los instrumentos de medición, ya sean indicadores, encuestas o test estadísticos, las nociones y los grupos de riesgo, el principio de precaución o la vigilancia epidemiológica, los programas al igual que las campañas de vacunación o de educación sanitaria, son productos de las relaciones científicas y políticas internacionales. Antes que regresar a las lecturas difusionistas que no tendrían más pertinencia hoy que la que tuvieron en el pasado, lo que debe ser planteado es, para retomar la expresión de Marc Augé (1994), el problema de la "contemporaneidad de los mundos". Se trata entonces de detectar cómo se elaboran y se intercambian los instrumentos intel ectuales mediante los cual es las real idades del cuerpo son aprehendidas: esta es la invitación que propone el estudio de Allan Young (1996) sobre la invención del síndrome de estrés postraumático para rendir cuenta de las taras físi cas de los veteranos estadouni denses de la guerra de Vietnam y desu universal ización por medio del DSM-IV, convertida en la "Biblia" dela psiquiatría mundial .

No hay que confundirse respecto del carácter de novedad radical de estos fenómenos. La gl obalización de la sal ud, tanto como de la economía o de la cultura, no es enteramente inédita. Como intenté mostrarlo siguiendo las peripecias del debate entre universal ismo y particularismo en la salud pública internacional, entre la medicina colonial y la medicina humanitaria (1997), no asistimos a una evolución lineal, pero sí, por un lado, a la tensión permanente entre posiciones contradictorias, y, por otro, a las inversiones cíclicas de las relaciones de fuerzas que se dan entre ellas. Aún más significativo, la relectura de los fenómenos contemporáneos presente en los trabajos de historiadores invita no sólo a relativizar su aparente excepcionalidad, al introducir en ella impresiones de déjà-vu (ya visto), sino, sobre todo, a descubrir las realidades actuales mediante la revelación de sus aspectos escondidos. En este sentido es revelador que la crítica más radical sobre la manera como ha sido planteado en África el problema de las causas y los desarrollos del sida provenga de historiadores. En efecto, desde una "perspectiva histórica", con baseen los trabajos real izados sobrela tuberculosisy Ia sífil is duranteel periodo col onial, Randall Packard y Paul Epstein 
(1992) evidencian la existencia durante los primeros años de la epidemia del sida de los mismos prejuicios estigmatizadores y los mismos presupuestos cultural istas que orientan tanto la investigación como la acción; aún más turbadora es su constatación sobre la falta de distancia de los antropólogos convocados por Ios responsables sanitarios y los médicos que no se mostraban más informados o más críticos que sus predecesores en el tiempo dela admi nistración col onial; es así como la interpretación sobre el origen y la progresión de la enfermedad hubiera podido colocarse entre las prácticas rituales y sobre todo las prácticas sexuales propicias, excluyendo todo análisis sobre las condiciones social es, económi cas y políticas que subyacen al desarrollo dela infección. ¿Cómo podría comprenderse la expl osión que experimentó la epidemia en África austral desde comienzos de los años 1990 sin referirse, como lo hace Dougl as Webb (1998) en el caso de Namibia, a una "epidemi ología social" de la infección, teniendo en cuenta, por un lado, los movimientos de población relacionados con la guerra, las migraciones de trabajo y la apertura de fronteras y, por otro, las relaciones de violencia instauradas por el régimen del apartheid y reforzadas por las frustraciones que suscitaba la persistencia delas desigual dades tras su desaparición oficial? ¿Y cómo no percibir el alcance simbólico y político del rechazo del gobierno de Sudáfrica contra la distribución parsimoniosa de medicamentos antiretroviral es que los países occidentales han propuesto recientemente para intentar reducir la diferencia creciente en la toma de responsabi lidad sobre la enfermedad en el mundo rico y en las sociedades pobres, rechazo que deja ver la marca de los contenciosos que protestaron desde el comi enzo de la epi demi a contra las relaciones entre el Nortey el Sur e, incluso, entre los blancos y los negros, tal como lo mostró Gilles Bibeau (1991)? Lo que está en juego en los escenarios africanos del sida no resul ta significante sal vo a la luz de una historia social y política en que las relaciones de poder internacionales tienen tanto lugar como las relaciones de poder dentro de las sociedades. El fracaso de los programas de prevención y la incapaci dad de la mayor parte de los anal istas para explicarlo tienen como causa esta dificultad de captar la enfermedad de otra forma que en su doble dimensión biológica y cultural, mientras quelas condiciones sociales y políticas de producción de la epidemia y sobre todo su gravedad -porque el sida no es sólo una infección queafecta mucho más frecuentementea los africanos, sino también 
una enfermedad por la que seestán muriendo muchos más y más rápidamente que los otros- se mantienen en la sombra. Como dice Paula Trei chler (1992), la historia del sida en el tercer mundo es también una "crónica del primer mundo", y especialmente de sus científicos.

Así pues, la pertinencia de una antropol ogía de la sal ud puede apreciarse al contemplar su capacidad de volver intel igibles los retos que sobrepasan el marco de lo que se ha convenido en Ila mar el sector de la salud. Puesto que si, como hemos visto, la producción de la salud consiste en la traducción de las realidades sociales al lenguaje sanitario, lo que habría que detectar e interpretar son los efectos de sentido así constituidos. De hecho, estos efectos de sentido son tanto más importantes de estudiar por su tendencia a escapar del anál isis mediante un doble mecanismo de opaci dad. Por un lado, la sal ud parece siempre basarse en el consenso. En torno al cuerpo sufriente, la legitimidad de su intervención se presenta como una evi dencia: ¿quién podría controvertir que se cuide a los enfermos o que se prevengan sus decesos? Por otro, la salud parece siempre asunto de especialistas. Sus discursos y sus dispositivos pretenden ofrecer soluciones técnicas para problemas concretos, independientemente de cualquier posición ideológica: ¿qué podrían hacer el ciudadano y con mayor motivo el antropólogo si son tan ajenos al saber biológico y medicinal? Es entonces a la vez contra la propensión compasiva y más allá de las apariencias técnicas que debe hacerse dela sal ud al go significante. Estos mecanismos de ocultamiento no son nunca tan poderosos como cuando operan dentro de las relaciones internacionales 0 , más precisamente, en el despliegue local de programas gl obales. Enseguida de la Conferencia de Nairobi de 1985 patrocinada por el Banco Mundial y la Organización Mundial de la Salud, que había hecho de la reducción de la mortalidad materna una prioridad internacional, fueron lanzados los primeros programas denominados "para una maternidad sin riesgo", queevidentementefueron acogi dos muy favorablemente en todos los países, y singularmente en América latina. Un poco en todos los lugares de este continente, y especial menteen Ecuador, en dondereal icéestudios sobreesta cuestión con Anne-Claire Defossez (1992: 2336), una política orientada hacia la salud materna fue final mente puesta en práctica sobre bases si mples: puesto que las mujeres mueren durante partos esencialmente carentes de cuidados obstétricos, hay que incitarlas a dar a luz en los 
centros de maternidad y, dado que el riesgo letal crece con cada nacimiento, se requiere desarrollar la planificación familiar. Y no faltaron antropólogos para confirmar que, efectivamente, "Ia mayor parte dela población rural, indígena o campesina, no acudealos servicios desalud, independientementedelos problemas de acceso, por razones cultural es que implican no sólo el nivel de educación, sino también más fundamental mentela existencia de un mundo simbólico desentido diferente". Sin embargo, dos presupuestos no fueron puestos en duda. Primero, la elección de acciones orientadas exclusivamentehaciala dimensión reproductiva dela salud delas mujeres. Segundo, Ia limitación del problema a un simple asunto médico que hal laba respuesta en la mejor adaptación de las poblaciones a su sistema de atención. Ahora bien, estos dos elementos son eminentemente problemáticos. Por un lado, en efecto, focal izar los programas sanitarios sobre la salud materna no sejustificaba epidemiológicamente, habiendo otras causas de deceso más frecuentes, especial mente los cánceres genitales, los abortos y la tubercul osis, ni políticamente, puesto que terminaban ratificandola restricción del papel social delas mujeres, que hacía parte desu dominación. Por otro, explicar las débiles tasas denacimi entos en hospital es a partir derazones culturales llevaba a ocultar las condi ci ones físicas y económicas del acceso a la atención, así como el tratamiento discriminatorio que recibían las mujeres indígenas durante su maternidad. Detrás de la doble legitimación de este programa, compasiva -la muerte de una madre, cuyos documentos oficiales recuerdan por lo demás las consecuencias sobre la salud de sus hijos- y técnica -implicando el fortal ecimiento delas redes de maternidad y la difusión de mensajes educativos-, puede encontrarse la salud reducida a sus dimensiones biol ógica-ejempl ificada por medio de la reproducción- y cultural -pensada en térmi nos de obstáculos-. Es entonces al precio de un trabajo crítico, centrado tanto sobre los procesos globales de enunciación de las reglas internacionales de la salud pública y sobre las sociedades locales donde son aplicadas, que puede develarseel si gnificado de acciones desalud quesuscitan un acuerdo tal en el mundo social, aunquea menudo se escapen de toda interpretación.

Este lazo entre lo local y lo gl obal encuentra probablemente sus figuras más emblemáticas en el inmigrante y el refugiado. Los movimientos poblacionales, ya sean voluntarios, en cuyo caso suelen estar estrictamente controlados, o forzados, por 
causa de la guerra o de la represión, insertan en el corazón de las sociedades contemporáneas a hombres y mujeres que conjugan la doble condición de ser extranjeros y desplazados. Prolongando la reflexión de Hannah Arendt (1982) sobrel os exiliados y los apátridas, podemos ver en los inmigrantes y los refugiados, ya sea que vivan en los campos del otro lado de las fronteras de su país o entre los nativos de los países que los reciben, los representantes de una nueva categoría social y política, "Ios pueblos sin estado". Ahora, si consideramos la evolución reciente de los textos y de las prácticas rel acionadas con el tema, no puede dejarse de constatar la importancia creciente que han adquirido las cuestiones del cuerpo, la sal ud, la vida en las gestiones internacionales y naci onales deestas poblaciones. No soIamente la medicina humanitaria se ha convertido en la institución más legítima de intervención dentro de los campos de refugiados a lo largo del planeta, sino además esta misma lógica humanitaria es la que tiende a prevalecer en el manejo que se le da a los inmigrantes en los países ricos: mientras que las perspectivas de epidemias y de hambrunas justifican el envío de médicos y de medicamentos hacia los terrenos lejanos a fin de evitar las "catástrofes humanitarias", se constata que la enfermedad, por más grave que sea, se vuelve para los extranjeros en situación irregular una causa cada vez más frecuente de regularización "por la razón humanitaria". En el principio deesta evolución, encontramos esta política de reconocimiento del ser sufriente y del cuerpo enfermo que había sido anteriormente designada como biolegitimi dad. Aquí todavía los retos en salud nos dicen más de lo que general mente pensamos sobre lo que fundamenta el lazo social y sobre la manera en que las bío-lógicas pesan hoy en la convivencia.

\footnotetext{
CONCLUSIÓN: LA SALUD, ENTRE POLÍTICAS DE LO VIVIENTE Y POLÍTICAS DE LA VIDA
}

I PROBABLEMENTE SITUACIONES NUEVAS Y DESAFÍOS INÉDITOS VENdrán a presentarse ante los antropól ogos, quienes en el futuro trabajarán sobre estas realidades en las que el cuerpo es sometido a los exámenes de la política, es aún más seguro que serán igual mente confrontados a hechos que requerirán las 


\section{Revista Colombiana \\ de Antropología

mi smas exigencias de su disciplina y a problemas que no han dejado de alimentar sus debates. En particular, a ellos les será planteado el problema de la selección y de la interpretación de sus objetos. En este texto he intentado mostrar el doble riesgo que habría en este campo si se limitara la exploración de las bíológicas a los más al tos puntos de sus manifestaciones, olvidando los rincones más oscuros donde se disputan a veces las diferencias de esperanza de vida de varias decenas de años, y si se restringiera el análisis dela enfermedad a sus dimensiones culturales o individuales, en detrimento de las aproximaciones históricas o políticas. Riesgo cuyo anuncio no se basa en una predicción, sino simplemente en el examen del pasado. Riesgo cuyas consecuencias no son simplemente científicas, sino que afectan también la posición de las ciencias social es en la ciudad.

La herencia de la teoría del biopoder ha tomado dos caminos distintos. El primero, sobre el cual trabaja Paul Rabinow, reivindica la tradición de Georges Canguilhem y de su filosofía de las ciencias. En éste se explora lo viviente y su conocimiento, la manera como los nuevos saberes implican nuevas relaciones de poder pero también desocialidad. El segundo, sobreel cual Giorgio Agamben realiza sus estudios, se inscribe en la filiación de Hannah Arendt y de su filosofía política. En este se estudia la vida y sus formas, cómo el poder se manifiesta en los cuerpos y cómo su existencia cívica se articula con la física. La política de lo viviente, que se despliega sobre el primer eje, tiene como espacio privilegiado el laboratorio de investigación. Esta pretende aprehender las transformaciones del humano por medio de las bío-lógicas. La política de la vida, que explora el segundo eje, tiene como horizonte final el campo de concentración. Esta intenta mostrar las bío-lógicas accionadas en la producción del hombre y de sus derechos. La posición aquí defendida es que política de lo viviente y política de la vida son las dos fases de la bíopolítica, que las cuestiones sobre lo humano y el hombre remiten ambas a un reto común de humanidad y, en fin, quela salud, tal como ha sido definida previamente, ofrece una perspectiva si no desíntesis, al menos sí una que pone en relación dos tradiciones filosóficas y dos dimensiones antropológicas. Lejos de mostrar universos de comprensión diferentes, las lógi cas sociales y los presupuestos moral es que sostienen hoy la fabricación del genoma y sus empleos potenciales, por un lado, la medicina humanitaria y sus implicaciones internacionales, por el otro, 
deben ser pensadas en conjunto, para así comprender los val ores implícitos que orientan las representaciones delo viviente y dela vida. Así mismo, las el ecciones estratégicas efectuadas por las empresas farmacéuticas en la búsqueda de nuevas moléculas o el abandono de antiguos medicamentos no están desvinculados de las realidades epidemiológi cas de las enfermedades parasitarias o infecciosas en el tercer mundo, y los unos y los otros traducen jerarquías implícitas de humanidad entre poblaciones solventes y no solventes y modal idades de expresión de las bío-políticas que las ciencias social es deben aprehender.

Si bien no puede evidentemente pretender el monopolio sobre este campo de investigación, la antropología de la salud, tal como he querido defenderla en este texto, puede aportar una contribución particular. Como antropología, tiene la vocación de unir la mirada mi nuciosa y atenta del trabajo etnográfico y la perspectiva más amplia del comparativismo, implícito o explícito, que siempre ha puesto en obra. En tanto que se interesa por la salud, ella teje a partir de realidades ordinarias los lazos entre las políticas de lo viviente y las políticas de la vida que, con seguridad, estarán entre los desafíos cruciales de los tiempos que se avecinan.

\section{REFERENCIAS BIBLIOGRÁfICAS}

AвÉLĖs, M. 1992. "Anthropologie politique de la modernité". L'Homme. 32 (121).

ACKERKNECHT, E. H. 1948. "Anticontagionism between 1821 and 1867". Bulletin of the History of Medicine. 22.

Agamben, G. 1997. Homo Sacer. Le pouvoir souverain et la vie nue. Seuil. París.

Appadural, A. 1996. Modernity at large. Cultural dimensions of globalization. University of Minnesota Press. Minneapolis.

ArendT, H. 1982. Les origines du totalitarisme. L'impérialisme. Seuil. París. 1995 Qu'est-ce que la politique? Seuil. París.

AugÉ, M. 1984. "Ordre biologique, ordre social. La maladie forme élémentaire de l'événement". En M. Augé y C. Herzlich (dir.). Le sens du mal. Anthropologie, sociologie, histoire de la maladie. Editions des archives contemporaines. París. 
1986. “L'anthropologie de la maladie”. L'Homme. 26 (1-2). 1994. Pour une anthropologie des mondes contemporains. Aubier. París.

BAYER, R. 1992. “Entering the second decade: The politics of prevention, the politics of neglect". En E. Fee y D. M. Fox (dir.). AIDS. The making of a chronic disease. University of California Press. Berkel ey.

BECKETT, K. 1996. "Culture and the politics of signification: The case of child sexual abuse". Social Problems. 43(1).

BenoIst, J. 1966. "Du social au biologique: etude de quelques interactions". L'Homme. 6 (1).

BibeAu, G. 1991 “L'Afrique, terre imaginaire du sida. La subversion du discours scientifique par le jeu des fantasmes". Anthropologie et sociétés. 15(2-3).

Bourdelais, P. 1994. L'âge de la vieillesse. Histoire du vieillissement de la population. Odile Jacob. París.

Bourdieu, P., L. WACQuANT. 1998. "Les ruses de la raison impérialiste". Actes de la recherche en sciences sociales. 121-22.

Browner, C. 1989. "Women, household and health in Latin America". Social Science and Medicine. 28 (5).

Cipolla, C. 1976. Public health and the medical profession in the Renaissance. Cambridge University Press. Cambridge.

CoRIN, E. 1978. "La possession comme langage dans un contexte de changement socio-culturel: Ierite Zebola". Anthropologie et sociétés. 2-3.

CURTIN, P. 1992. "Medical knowledge and urban planning in Colonial tropical Africa". En S. Feierman y J. Janzen (dir.). The social basis of health and healing in Africa. University of California Press. Berkel ey.

Dagognet, F. 1988. La maîtrise du vivant. Hachette. París.

Devereux, G. 1970. Essais d'ethnopsychiatrie générale. Gallimard. París.

Douglas, M. 1992. Risk and blame. Essays in cultural theory. Routledge. Londres.

Doyal, L., Pennell, I. 1979. The political economy of health. Pluto Press. Londres.

Dozon, J. P. 1985 "Quand les pastoriens traquaient la maladie du sommeil". Sciences sociales et santé. 3(34).

FabregA, H. 1971 "Medical anthropology". Biennal Review of Anthropology. Stanford University Press. Stanford. 
FAINZANG, S. 1989. Pour une anthropologie de la maladie en France. Un regard africaniste. Cahiers de l'Homme. París.

FARMER, P. 1992. AIDS and accusation. Haiti and the geography of blame. University of California Press. Berkeley.

Fassin, D. 1996. L'espace politique de la santé. Essai de généalogie. Presses Universitaires de France. París.

1997. “L'international isation de la santé, entre cultural isme et universalisme". Esprit. 229.

1998a. "Les politiques de la médical isation. Avant-propos". En P. Aïach y D. Delanoë (dir.). L'ère de la médicalisation. Anthropos. París.

1998b. "Politique des corps et gouvernement des villes". En D. Fassin (dir.). Les figures urbaines de la santé publique. Enquête sur des expériences locales. La Découverte. París.

1999. Les enjeux politiques de la santé. Etudes sénégalaises, équatoriennes et françaises. Karthala. París.

Fassin, D., A. C. Defossez. 1992. “Une liaison dangereuse. Sciences sociales et santé publique dans les programmes de réduction de la mortalité maternelle en Equateur". Cahiers de sciences humaines. 28 (1).

Feierman, S., J. JANZEN (dir.). 1992. The social basis of health and healing in Africa. University of California Press. Berkeley.

Foster, G. M. 1976. “Disease etiologies in non-Western medical systems". American Anthropologist. 78.

Foucault, M. 1976. Histoire de la sexualité. 1 La volonté de savoir. Gallimard. París.

1984. Histoire de la sexualité. 2. L'usage des plaisirs. 3 Le souci de soi. Gallimard. París.

1994. Dits et écrits, 1954 1988 Gallimard. París.

Freund, J. 1986. L'essence du politique. Sirey. París.

Gadamer, H. G. 1998. Philosophie de la santé. Grasset-Mollat. París.

GAINES, A. D. 1998. "From margin to center: From medical anthropology to cutural studies of science". American Anthropologist. 100 (1).

Geertz, C. 1986. Savoir local, savoir global. Les lieux du savoir. Presses universitaires de France. París.

Genest, S. 1978. “Introduction à l'ethnomédecine. Essais de synthèse”. Anthropologie et sociétés. 2-3.

Godelier, M., M. Panoff (dir.). 1998. La production du corps. Approches 
anthropologiques et historiques. Editions des Archives contemporaines. Amsterdan.

GooD, B. J. 1994. Medicine, rationality, and experience. An anthropological perspective. Cambridge University Press. Cambridge.

HAHN, R. A. 1999. "Anthropology and the enhancement of public heal th Practice". En R. A. Hahn (dir.). Anthropology in public health. Bridging differences in culture and society. Oxford University Press. Oxford.

Hatzfeld, H. 1971 Du paupérisme à la sécurité sociale, 1840-1950. Armand Colin. París.

JANZEN, J. 1978. The quest for therapy. Medical pluralism in lower Zaire. University of California Press. Berkeley.

KEARNEY, M. 1995 “Thelocal and the gl obal: The anthropology of gl obalization and transnationalism". Annual Review of Anthropology. 24.

Kleinman, A. 1980. Patients and healers in the context of culture. An exploration of the borderland between anthropology, medicine and psychiatry. University of California Press. Berkeley.

--------. 1988. The illness narratives: Suffering, healing, and the human condition. Basic Books. Nueva York.

. 1995 Writing at the margin. Discourse between anthropology and medicine. University of California Press. Berkeley.

LA BeRGE, A. F. 1992. Mission and method. The early nineteenth century French public health movement. Cambridge University Press. Cambridge.

Latour, B., S. Woolgar. 1993 La vie de laboratoire. La production des faits scientifiques. La Découverte. París.

Lock, M., N. Scheper-Hughes. 1990. "A critical-interpretive approach in medical anthropology: Rituals and routines of discipline and dissent". En T. M. Johnson y C. F. Sargent (dir.). Medical anthropology. A handbook of theory and method. Greenwood Press. Nueva York.

Lovell, A., I. Féronı. 1998، "Sida-toxicomanie. Un objet hybride de la nouvellesanté publiqueà Marseille". En D. Fassin (dir.). Les figures urbaines de la santé publique. Enquête sur des expériences locales. La Découverte. París.

Lyons, M. 1988. "Sl eeping sickness, Colonial medicine and Imperial ism: Some connections in the Belgian Congo". En R. McLeod y M. Lewis (dir.). Disease, medicine and empire. Perspectives on Western medicine and the experience of European expansion. Routledge. Londres. 
McCulloch, J. 1994. Colonial Psychiatry and the 'African mind'. Cambridge University Press. Cambridge.

Marks, S., N. Anderson. 1988. "Typhus and social control in South Africa, 1917-1950". En R. McLeod y M. Lewis (dir.). Disease, medicine and empire. Perspectives on Western medicine and the experience of European expansion. Routledge. Londres.

MASSÉ, R. 1995 Culture et santé publique. Les contributions de I'anthropologie à la prévention et à la promotion de la santé. Gaëtan Morin. Montreal.

Mitrani, P. 1982. "Aspects de la recherche dans le domai ne des sciences sociales et de la médecine". L'Homme. 22 (2).

MoRgAn, L. 1990. "The medicalization of anthropology: A critical perspective on the critical-clinical debate". Social Science and Medicine. 30 (9).

MoRSEY, S. 1990. "Political economy in medical athropology". En T. M. Johnson y C. F. Sargent (dir.). Medical anthropology. A handbook of theory and method. Greenwood Press. Nueva York.

NelKin, D., S. LindeE. 1998. “Du gène comme icône culturelle". La Recherche. 311

Nichter M., 1994. "IIIness semantics and international health: The weak lungs/TB complex in the Philippines". Social Science and Medicine. 38 (5).

Ogien, A. 1994. "L'usage de drogues peut-il être un objet de recherche". En A. Ogien y P. Mignon (dir.). La demande sociale de drogues. La Documentation française. París.

PACKARD, R. 1989. "Industrial production, health and disease in SubSaharan Africa”. Social Science and Medicine. 28 (5).

1992, "Industrialization, rural poverty, and Tuberculosis in South Africa, 1850-1950". En S. Fei erman y J. Janzen (dir.). The social basis of health and healing in Africa. University of California Press. Berkeley.

PFoHL, S. 1977. "The 'Discovery' of child abuse”. Social Problems. 24.

Rabinow, P. 1989. French modern: Norms and forms of the social environment. MIT Press. Cambridge.

1996. Essays on the anthropology of reason. Princeton University Press. Princeton.

1999. French DNA. Trouble in Purgatory. University of Chicago Press. Chicago.

Ranger, T. 1992. "Plagues of beasts and men: Prophetic responses to 
epidemic in Eastern and Southern Africa". En T. Ranger y P. Slack (dir.). Epidemics and ideas. Essays on the historical perception of pstilence. Cambridge University Press. Cambridge.

ReVel, J. 1994. "Micro-analyse et construction du social”. En J. Revel (dir.). Jeux d'échelles. La micro-analyse à I'expérience. Hautes Etudes-Gallimard-Seuil. París.

Scheper-Hughes, N. 1992. Death without weeping. The violence of everyday life in Brazil. University of California Press. Berkeley.

Sсотсн, N. C. 1963 "A medical anthropology". Biennal Review of Anthropology. Stanford University Press. Stanford.

Sindzingre, N., A. Zemplénı. 1982. "Anthropologie de la maladie". Bulletin d'Ethnomédecine. 15

SINGER, M. 1989. "The coming of age of critical medical anthropology". Social Science and Medicine. 28.

1995 "Beyond the Ivory Tower: Critical praxis in medical anthropology". Medical Anthropology Quarterly. 9 (1).

Steffen, M. 1995 Les politiques publiques face au défi du sida. Comparaison internationale dans quatre pays européens: France, Grande-Bretagne, Allemagne, Italie. CERAT. Grenoble.

TAussig, M. 1987. Shamanism, colonialism, and the wild man. A sudy in terror and healing. University of Chicago Press. Chicago.

Thébaud-Mony, A. 1991 La reconnaissance des maladies professionnelles. La Documentation française. París.

TreICHLeR, P. 1992. "AIDS and HIV Infection in the Third World: A First World chronicle". E. Fee y D. M. Fox (dir.). AIDS. The making of a chronic disease. University of California Press. Berkeley.

Turner, B. 1992. Regulating bodies. Essays in medical sociology. Routledge. Londres.

VAUGHAN, M. 1992. "Famine analysis and family relations: Nyasaland in 1949'. En S. Feierman y J. Janzen (dir.). The social basis of health and healing in Africa. University of California Press. Berkeley.

Vigarello, G. 1993 Le sain et le malsain. Santé et mieux-être depuis le Moyen Age. Seuil. París.

1998. Histoire du viol, xvie-Xxe siècle. Seuil. París.

WALter, A. 1983 "Ethnomédecine et anthropologie médicale: bilan et perspectives". Cahiers ORSTOM, Série Sciences Humaines. 18 (4).

WEBB, D. 1998. "The sexual and economic politics of reintegration: HIV/AIDS and the question of stability". En D. Simon (dir.). South 
Africa in Southern Africa. Reconfiguring the Region. James Currey. Oxford.

WeBer, M. 1978. Economy and society. University of California Press. Berkeley (primera edición en alemán, 1921).

Woolgar, S., D. Pawluch. 1985 “Ontological gerrymandering: The anatomy of social problems explanations". Social Problems. 32 (3).

YoDeR, S. 1997. "Negotiating relevance: Belief, knowledge, and practice in international health projects". Medical Anthropology Quarterly. 1(2).

Young, A. 1996. The harmony of illusions. An ethnographic account of post-traumatic stress disorder. Princeton University Press. Princeton.

Zimmermann, 1995 Généalogie des médecines douces. De I'Inde à I'Occident. Presses Universitaires de France. París. 